\title{
Modelling the generation of dusty marine aerosol by expeditionary data and remote sensing methods over the Black Sea region
}

\author{
$A$ Papkova ${ }^{1,}, S$ Papkov ${ }^{2}$, and $D$ Shukalo ${ }^{1}$ \\ ${ }^{1}$ Marine Hydrophysical Institute of RAS, Sevastopol, 299011, Russia \\ ${ }^{2}$ Sevastopol State University, Sevastopol, 299053, Russia
}

\begin{abstract}
During a long-range transport, Sahara dust is naturally mixed with other aerosols, including maritime. At present, the mixing of these types of marine and dust aerosols is of particular interest, since it is important to correctly estimate the ionic and mass balance of aerosol particles. This problem is caused by the need for a reliable determination of the aerosol source and for correct atmospheric correction of satellite data. An analysis was made of the correlation between the change in the AOT parameter and the dates of dust transport from the Sahara to the Black Sea region. The analysis results confirmed the fact that the presence of dust aerosol over the Black Sea water area has a strong effect on the AOT indicator at all wavelengths, increasing the parameter almost by 2 times. This fact is correspondent to the generation of a secondary type of aerosol, namely, dusty marine aerosol. Analysis of CALIPSO aerosol subtype maps also revealed the presence of dusty marine aerosol with corresponding depolarization coefficients.
\end{abstract}

\section{Introduction}

Regular observations of optical and microstructural aerosol characteristics with a high spatial-temporal resolution are necessary for high-quality monitoring of the ecological state of the atmosphere, study of climate formation processes, improvement of forecast accuracy, and solution of many other geophysical problems [1].

A high dust load from the Sahara Desert is recorded annually over the Black Sea region. It is the dust aerosol that determines the variability of the incident solar radiation and radiation reflected from the Earth. These interactions are regulated not only by the spacetime distribution, but also by its microphysical, optical, and chemical properties [2]. In turn, sea aerosol (marine aerosol) also makes a significant contribution to the global aerosol load, as it is emitted from a large surface area and has the ability to strongly influence the reflective properties and lifetime of clouds, which in turn affects the entire climate system [3].

During a long-range transport, Sahara dust is naturally mixed with other aerosols, including maritime. At present, the mixing of these types of marine and dust aerosols is of particular interest, since it is important to correctly estimate the ionic and mass balance of

* Corresponding author: hanna.papkova@gmail.com 
aerosol particles in dusty marine aerosol. This task is caused by the need for a reliable determination of the aerosol source and for correct atmospheric correction of satellite data. Previous studies using the CALIPSO atmospheric aerosol typing algorithms [4] have shown a high content of dusty marine aerosol over the Crimean coast.

The goal of a work is to study the effect of overestimated concentrations of dust aerosol on the optical characteristics of marine aerosol using expeditionary data on the Black Sea, annually provided by the AERONET network (MAN) and satellite data from the CALIOP radiometer and, consequently, modeling of the mechanisms of generation of dusty marine aerosol.

The aerosol optical thickness (AOT) parameter was used as the main optical characteristic of the state of the atmosphere, as it indicates the aerosol turbidity of the atmosphere and the ecological state of the air basin. In addition to this, the values of the particle depolarization coefficients were used - is the intensity ratio between the perpendicular component and the parallel component of Raman scattered light, provided by CALIPSO satellite.

Similar studies have been carried out to investigate the mixing of sea and dust aerosols for the Mediterranean Sea and Atlantic Ocean, by using backscatter-related Ångström exponents, microphysical properties of aerosol particles are characterized qualitatively [5]. Source apportionment of atmospheric aerosol in a marine dusty environment by ionic/composition mass balance (IMB) in Santiago, the largest island of Cabo Verde was also considered, where dust was also reported as the dominant source of mixed marine aerosol generation [6].

\section{Methods and research area}

In the present study, a set of experimental data on the optical properties of marine aerosol was collected using data from AERONET. To identify the presence of absorbing aerosol of dust origin over the Black Sea, 7-day return trajectories of aerosol generation AERONET and satellite maps of tropospheric aerosols subtypes are used. These data provided by the CALIPSO (Cloud-Aerosol Lidar and Infrared Pathfinder Satellite Observation) remote sensing tool, which was launched in 2006 as part of NASA EOS software.

\subsection{AERONET network}

One of the most effective means of studying the characteristics of atmospheric aerosol is the global network of observation ground automated stations AERONET (Aerosol ROboties NETwork). To this day, AERONET is one of the ground-based atmospheric monitoring networks used by scientists around the world. It includes more than 200 stations located in different parts of the world, observations at which are carried out with the same accuracy. The Marine Aerosol Network (MAN) component AERONET provides aerosol optical measurements with Microtops II solar photometers on board research vessels. These data provide an alternative to land-based observations and also establish verification points for satellite and aerosol transport models. Microdevices currently on the AERONET network have five channels, but can have one of two configurations: 340, 440, 675, 870, $936 \mathrm{~nm}$ or 440, 500, 675, 870 and $936 \mathrm{~nm}$. In addition, the device has built-in temperature and pressure sensors, as well as the ability to register exact time and geographic position using GPS. Microtops instruments are calibrated at NASA's Goddard Calibration Center at the Space Flight Center (GSFC) using a transfer calibration procedure between Microtops and Cimel's main solar photometer. In general, the estimated uncertainty in the optical thickness of the aerosol in each channel does not exceed plus or minus 0.02. For the Black Sea, from 2009 inclusive, regular voyages with corresponding measurements on R.V. Academic belongs to 
the Bulgarian Academy of Sciences and is managed by the Institute of Oceanology (Varna) [7].

\subsection{CALIPSO mission}

In this research was added a new source which providing measurements of the atmosphere optical characteristics to carry out a comprehensive comparative analysis of aerosol data. This new source is US-French Research CALIPSO satellite, launched under NASA EOS program for the aerosols and clouds measurements. Main measuring instrument CALIPSO is three channel radiometer (working channel wavelength is 8.65 microns, 10.6 microns and 12.05 microns). For the reason that the system is a lidar it CALIPSO is fully polarized in one direction. Scattering of the atmosphere changes the incident polarization and the measurement of the depolarization degree provides a wealth of information about the nature of the particles, especially their geometry atmosphere changes the incident polarization and the measurement of the depolarization degree provides a wealth of information about the nature of the particles, especially their geometry. Based on built-in algorithms, CALIPSO provides atmospheric aerosol maps by entering the corresponding satellite flight path. In this work, we use the latest version of this algorithm, described in the work [8].

\section{Results}

Annually, since 2009, the research vessel Akademik has performed from one to three voyages in the Black Sea. As mentioned earlier, the aerosol optical thickness (AOT) parameter was used as the main optical characteristic of the state of the atmosphere.

For each of the dates of the expedition, an analysis of the generation of aerosol was carried out, thus, out of the total number of days (94), 20 dates with a high concentration of absorbing aerosol of natural origin were recorded. As noted, this procedure was carried out using satellite maps of tropospheric aerosol subtypes, CALIPSO (Figure 1) and 7-day return trajectories of aerosol nucleation AERONET (Figure 2). 

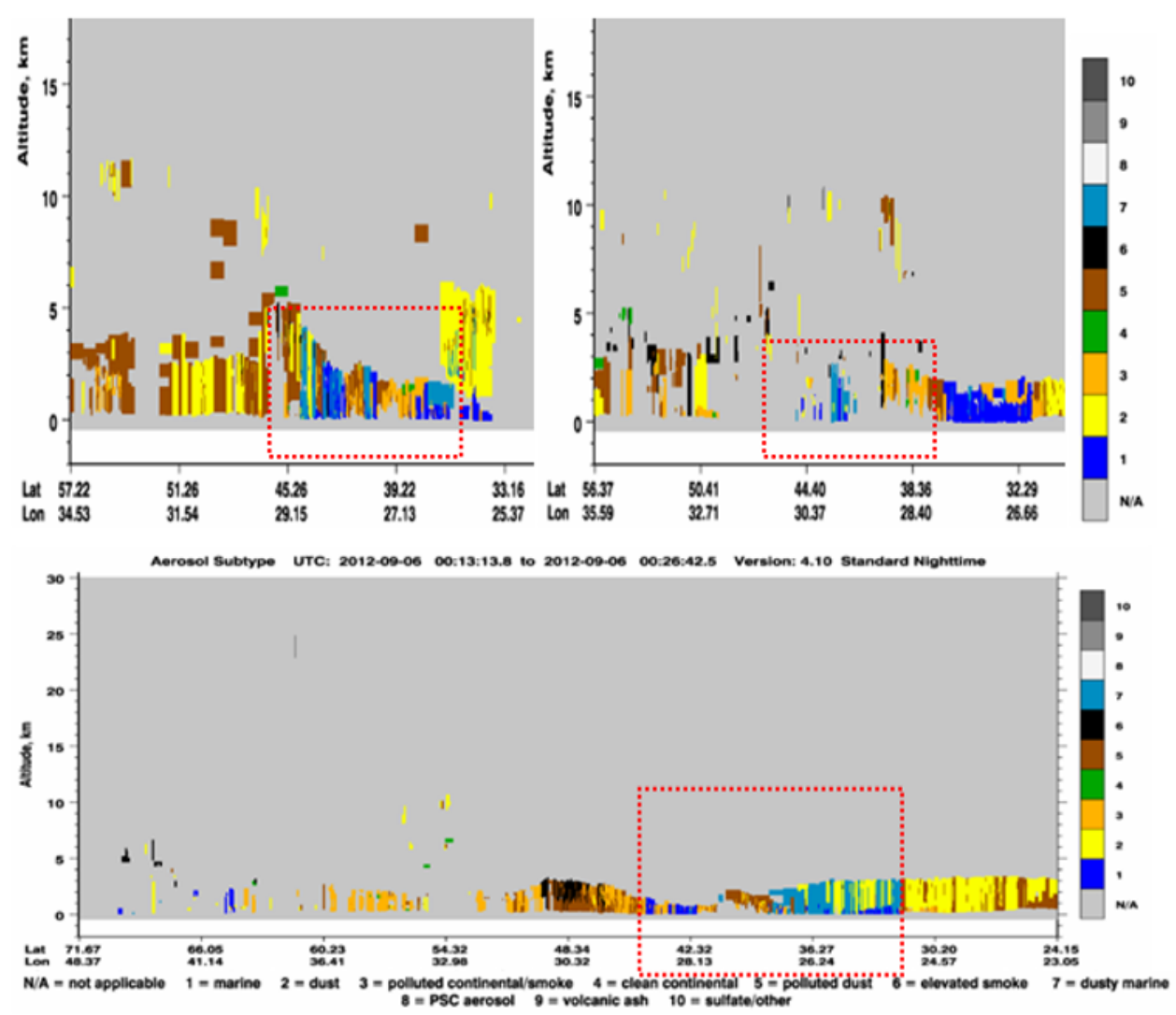

Fig. 1. Registration of finding a mixed dust aerosol by means of the CALIPSO satellite models on the days of dust transfer (26.05.2015; 01.06.2014; 09.06.2012).

Starting Location Station (red dot): Sevastopol

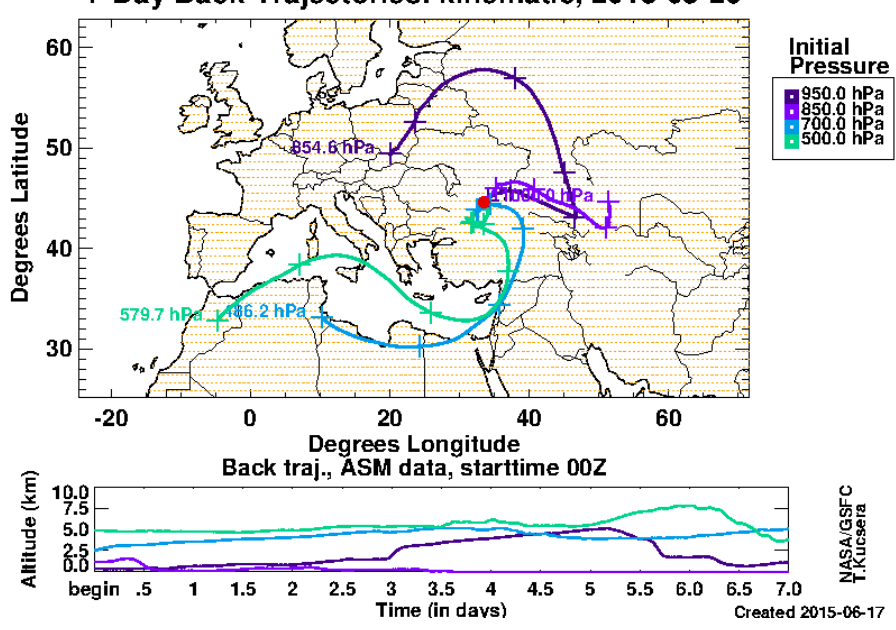

Fig. 2. Registration of dust transport from the Sahara over the Black Sea region using AERONET trajectories on 05.26.2015. 
Using the Microtops II instrument, an AOT data set of 5353 values for the Black Sea region was obtained. The input data is checked for clouds and pointing errors, but may not have a final calibration (level 1.5). Mathematical modeling of AOT changes and the degree of influence of the distance of the research vessel on this parameter was performed using a code written in Python using built-in libraries (Pandas, Geopandas, NumPy) (Table 1)

Table 1. Values of aerosol optical thickness on the days of expeditions in the Black Sea, taking into account the mean square deviation.

\begin{tabular}{|c|c|c|c|c|c|}
\hline & AOT $_{440}$ & AOT $_{500}$ & AOT 675 & AOT870 & AOT $_{1020}$ \\
\hline Dust transfer & $0.30 \pm 0.06$ & $0.26 \pm 0.05$ & $0.15 \pm 0.03$ & $0.10 \pm 0.02$ & $0.08 \pm 0.01$ \\
\hline $\begin{array}{c}\text { Clean } \\
\text { atmosphere }\end{array}$ & $0.15 \pm 0.05$ & $0.13 \pm 0.04$ & $0.08 \pm 0.02$ & $0.06 \pm 0.02$ & $0.05 \pm 0.01$ \\
\hline
\end{tabular}

Based on Table 1, it follows that the presence of dust aerosol over the Black Sea has a strong effect on the AOT parameter. This statement is also correct for the coordinates that are maximally distant from the land. Analyzing these statistics, it can be assumed that during the study, the average values of the AOT parameter were obtained for pure marine aerosol (clean atmosphere) and mixed dust aerosol (the presence of dust aerosol over the water area). Data from the CALIPSO satellite version V4 (2018) also showed a significant presence of dusty marine aerosol, which also agrees with the values of the depolarization coefficients $(\delta \mathrm{p})$ According to the V4 [6] algorithm, if $\delta p<0.05$, the aerosol is classified as pure marine, if $0.05>\delta p>0.2$ - dusty sea aerosol (Figure 3).

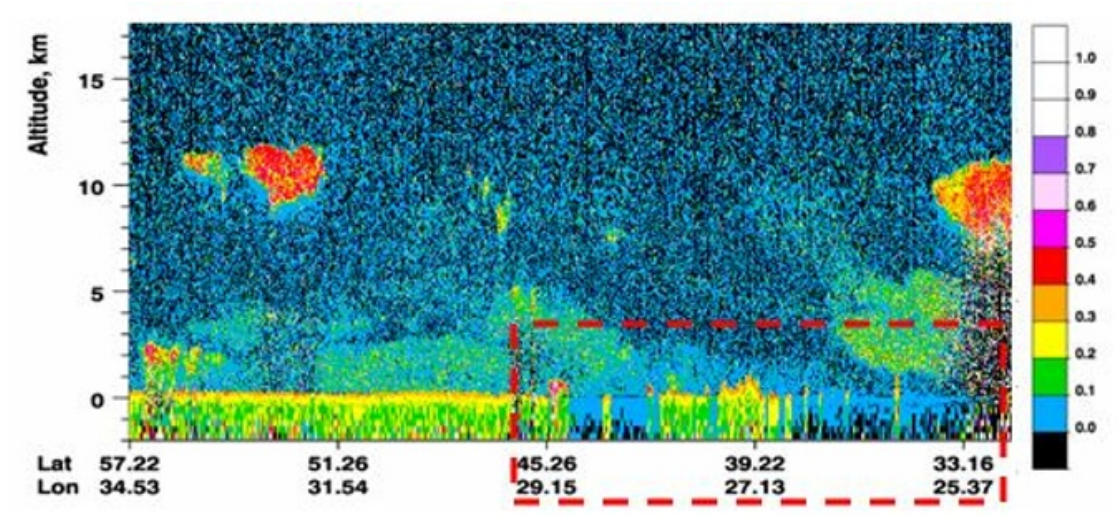

Fig. 3. Map of depolarization coefficients values on 26.05.2015 according to the CALIPSO models.

\section{Conclusions}

A long-term array of data on aerosol optical thickness over the Black Sea region was collected as a part of scientific expeditions in the Black Sea. An analysis was made of the correlation between the change in the AOT parameter and the dates of dust transport from the Sahara and Syria. The analysis of the results has confirmed the fact that the presence of dust aerosol over the Black Sea water area has a strong effect on the AOT indicator at all wavelengths, increasing the parameter almost by 2 times. This fact is correspondent to the generation of a secondary type of aerosol, namely, dusty marine aerosol. Analysis of CALIPSO aerosol subtype maps has also revealed the presence of dusty marine aerosol with corresponding depolarization coefficients. Thus, it is important to correctly estimate the contribution of the absorbing aerosol to the aerosol optical thickness, even in the most distant coordinates from the land for reliable atmospheric correction of satellite data. 


\section{Acknowledgments}

The study was carried out with the financial support of the Russian Foundation for Basic Research, scientific project No. 19-35-90066, and within the framework of the state assignment programs of the Marine Hydrophysical Institute of the Russian Academy of Sciences on the topic No. 0827-2019-0002.

The authors thank the AERONET network for providing the expedition data of the research vessel RV Akademik belongs to the Bulgarian Academy of Sciences and is operated by the Institute of Oceanology (Varna) and Dr. Giuseppe Zibordi from the European Commission - Joint Research Center (Ispra, Italy) for taking measurements during the expedition. We would also like to express our gratitude to Tom Kucsera, Brent Holben and the Gene Feldman team of National Aeronautics and Space Administration - NASA for the calculations of the BTA data and the CALIPSO satellite data.

\section{References}

1. Zhining T, Zhining Y, Mian C 2015 A NU-WRF Study over the United States Atmosphere 6 1045-1068

2. Kalinskaya D V, Varenik A V, Papkova A S 2018 Sovremennye Problemy Distantsionnogo Zondirovaniya Zemli iz Kosmosa 15(3) 217-225

3. Fitzgerald J W 1991 Atmospheric Environment Part A General Topics 25(3) 533-545

4. Papkova A S, Papkov S O, Shukalo D M 2020 Sovremennye Problemy Distantsionnogo Zondirovaniya Zemli iz Kosmosa 17(1) 234-242

5. Zahary Y, et al 2019 20th International Conference and School on Quantum Electronics: Laser Physics and Applications 110471104715

6. Cardoso J 2018 et al Atmospheric Chemistry and Physics 18 13215-13230

7. Smirnov A et al 2009 J Geophys 114 D06204

8. Kim M H et al 2018 Atmospheric Measurements Techniques 11 6107-6135 